\title{
Pliocene sea level revisited: Is there more than meets the eye?
}

\author{
Georgia R. Grant ${ }^{1}$ and Tim R. Naish ${ }^{2}$
}

We reassess available studies of mid-Pliocene sea level and provide new estimates. The relative amplitude of glacialinterglacial sea-level variability was likely between $6.2 \mathrm{~m}$ (16th percentile) and $16.7 \mathrm{~m}$ (84th percentile), leading to an average ice-volume sensitivity of $4 \mathrm{~m} /{ }^{\circ} \mathrm{C}$ sea-level equivalent.

The mid-Pliocene warm period (MPWP), 3.3-3 million years ago, is the most recent time when Earth's climate reached equilibrium under atmospheric $\mathrm{CO}_{2}$ concentration of $\sim 400 \mathrm{ppm}$, with global temperatures $2-3^{\circ} \mathrm{C}$ higher than during the pre-industrial era (1750 CE; Masson-Delmotte et al. 2013). Sea-level reconstructions for this period suggest peak interglacial sea levels were up to $40 \mathrm{~m}$ above present (e.g. Dutton et al. 2015), implying loss of the Greenland, West Antarctic, and marine sectors of the East Antarctic ice sheets, as well as partial loss of the terrestrial East Antarctic Ice Sheet.

\section{Peak magnitude vs relative amplitude} Reconstructions of peak MPWP interglacial sea level are usually reported as global mean sea level (GMSL) with reference to the Holocene. While peak GMSL provides insight into the volume of polar ice-sheet loss and the magnitude of sea-level rise that might be expected because of near-future climate change, it does not capture the full amplitude of glacial-interglacial ice-volume change (Fig. 1), or the full amplitude of sealevel change in response to climate forcing, which may lead to an underestimation of ice volume sensitivity (defined here as the change in sea level equivalent (SLE) of ice volume (m) per $1^{\circ} \mathrm{C}$ of temperature change). For example, calibrations of the benthic $\delta^{18} \mathrm{O}$ proxy of global ice volume and sea level (e.g. Lisiecki and Raymo 2005) place the sea level during many Pliocene glacials below that of present-day, implying larger-than-present ice-sheet configurations at the beginning of deglaciations. This has significant implications for estimating both the amplitude and rate of sea-level rise in response to relatively small amounts of global warming.

We have categorized "continuous" sedimentary sequences used in reconstructing the amplitude of MPWP GMSL into "direct" (e.g. geologic) and "indirect" (e.g. calibrations of foraminifera $\delta^{18} \mathrm{O}$ curves; Fig. 1; Fig. 2a). We compare these glacial-interglacial amplitudes with estimates of the peak MPWP GMSL derived from "direct" but "discontinuous" geological remnants preserved in the far field (e.g. paleo shorelines). In addition, we use ice-volume constraints provided by polar continental margin drill cores (Fig. 1; Fig. 2b). Finally, we provide a quantitative reassessment of peak GMSL and the amplitude of glacial-interglacial global sea-level change during MPWP.

\section{Where the uncertainty lies}

Many of these peak GMSL estimates have not been corrected for regional deviations due to tectonics, glacio-isostatic adjustment (GIA), or dynamic topography. Deformation of the Earth may cause local sea-level changes large enough to either cancel out or double the amplitude of the ice-volume contribution (Raymo et al. 2011). Although some recent studies have attempted to correct for these regional effects, significant uncertainty remains concerning the role of dynamic topography (Rovere et al. 2015; Dumitru et al. 2019).

Deep-ocean foraminiferal $\delta^{18} \mathrm{O}$ records provide one of the most detailed proxies for glacial-interglacial climate variability during the Pliocene; however, the signal is affected by ocean temperature, ice-sheet $\delta^{18} \mathrm{O}$ composition and ice volume (Lisiecki and Raymo 2005). Several studies have used $\mathrm{Mg} / \mathrm{Ca}$ paleothermometry to calibrate benthic $\delta^{18} \mathrm{O}$ records (Dwyer and Chandler 2009;

Sosdian and Rosenthal 2009; Miller et al. 2012; Miller et al. 2020). Another approach incorporates sill-depth and salinity changes from the Mediterranean to calibrate sea level in a planktic $\delta^{18} \mathrm{O}$ record (Rohling et al. 2014), but large uncertainties $(> \pm 10 \mathrm{~m})$ remain. On the other hand, sea-level calibrations of the benthic $\delta^{18} \mathrm{O}$ record, constrained by backstripped continental margins (sedimentary sequences that have tectonic subsidence and compaction effects removed; e.g. Naish and Wilson 2009; Miller et al. 2012; Miller et al. 2020), are often hampered by the limited precision inherent to foraminiferal paleodepth indicators and the influence of sediment erosion during sea-level lowstands, leading to underestimation of the full amplitude of sea-level change.

In contrast, Grant et al. (2019) derived a continuous but floating sea-level record

\section{Mid-Pliocene warm period (MPWP) sea level constraints}

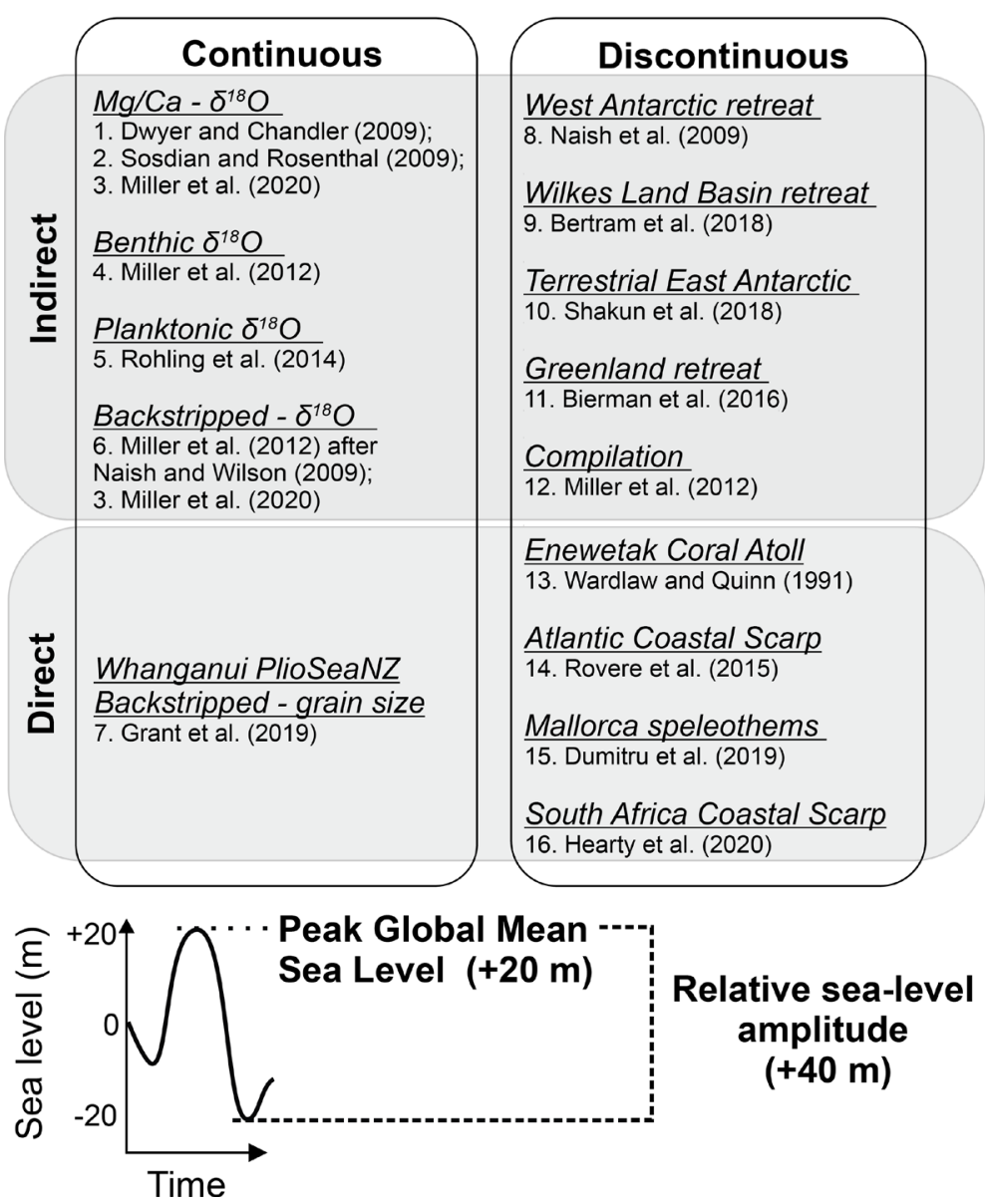

Figure 1: Studies of MPWP sea-level estimates (shown in Fig. 2) are placed into four categories. The schematic sea-level curve illustrates the difference between peak GMSL as a single point referenced to a datum, and relative amplitude of sea-level change over the glacial-interglacial range. 
a)

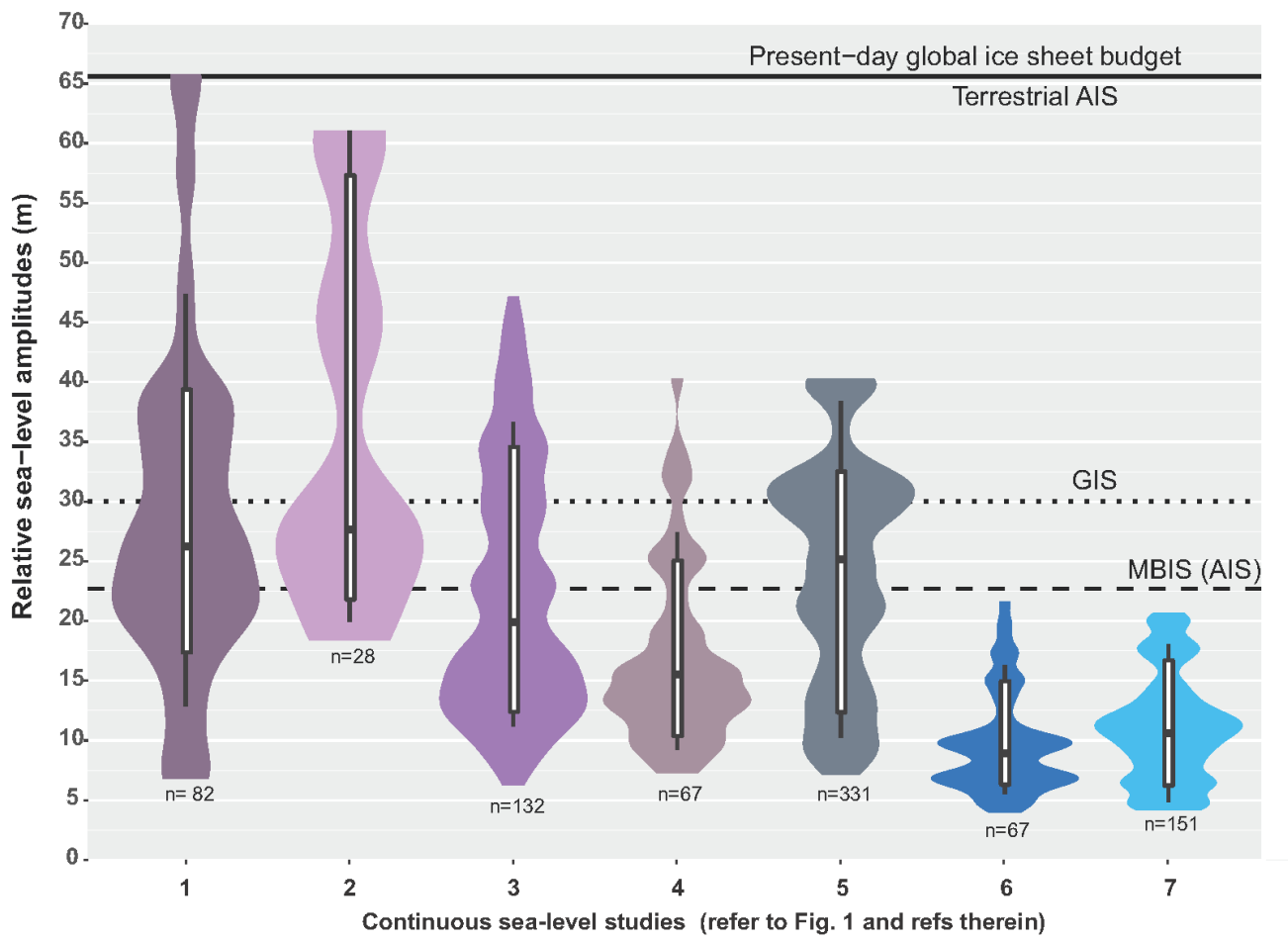

b)
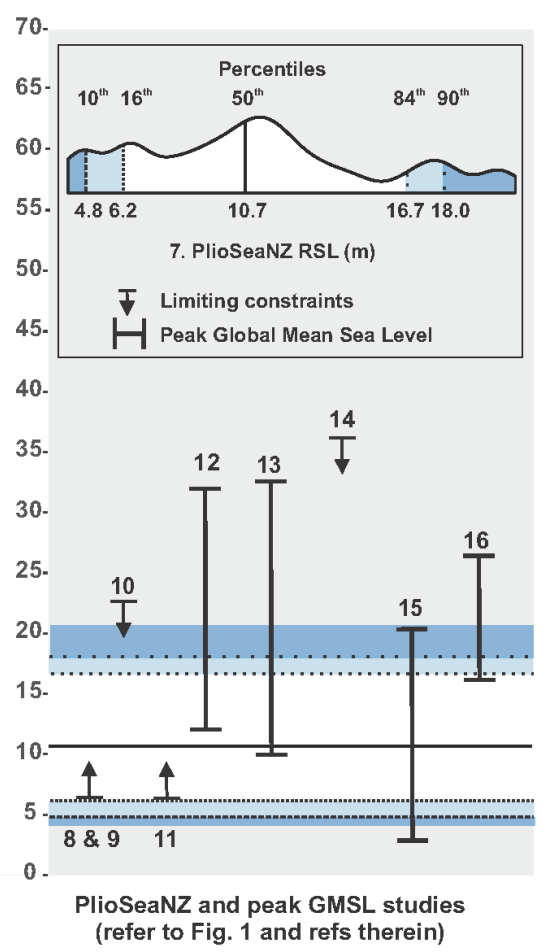

Figure 2: (A) Frequency distributions of relative sea-level amplitudes for continuous studies of the MPWP with box and whisker plots for the 10th, 16th, 50th, 84th, and 90th percentiles with cumulative sea-level equivalent shown for marine-based ice sheets (MBIS) of Antarctic Ice Sheets (AIS), Greenland Ice Sheet (GIS) and terrestrial AIS; and

(B) PlioSeaNZ relative amplitude percentiles shown as horizontal colored bars in comparison to peak GMSL estimates and geologic constraints on ice-sheet contribution to sea level. An R script and R workspace for these plots are available on request from the author. Note that Study 2 only spans part of the MPWP.

for the MPWP termed PlioSeaNZ from Whanganui, New Zealand, that is completely independent of the global benthic $\delta^{18} \mathrm{O}$ record. It calculates a theoretical relationship between sediment transport by waves and water depth, and applies the technique to grain size in a well-dated, continuous, shallow marine sequence. Water-depth variations obtained in this way, after corrections for compaction, tectonic subsidence, and glacial isostatic adjustment (GIA), yield the full amplitude of glacial-interglacial sea-level variability with precision of $\pm 5 \mathrm{~m}$ and are relatively unaffected by dynamic topography.

\section{Revisited estimates}

The amplitude of glacial-to-interglacial sea-level change in continuous sedimentary records spanning MPWP (Fig. 1 and references therein) are compared in Figure 2a. The relative amplitude (maximum range) is calculated for a moving 20,000-year window at variable time steps for each record determined by sample spacing in the individual records. The 20,000-year window is chosen to capture the minimum orbital frequency of change. Also plotted are the percentiles (10th, 16th, 50th, 84th, 90th) for the amplitude-frequency distributions.

If these amplitudes are treated as GMSL change above present and the current global ice-sheet budget is considered the potential meltwater source, the sea-level equivalent of marine-based portions (MBIS) of the Antarctic lce Sheet can account for $22.7 \mathrm{~m}$, the Greenland Ice Sheet contains $7.3 \mathrm{~m}$, and an additional $35.6 \mathrm{~m}$ is available from terrestrial sectors of the Antarctic Ice Sheet. Amplitudes $>+30 \mathrm{~m}$ can only be explained by melting the terrestrial sectors of the Antarctic Ice Sheet, and/or by having more ice on the Northern Hemisphere continents during glacial periods than can be explained by the available geological data (e.g. Thiede et al. 2011). Larger-than-Holocene Antarctic glacial ice volumes cannot be excluded by proximal geological data for every glacial of the MPWP (Naish et al. 2009), but retreat of the East Antarctic lce Sheet since eight million years ago is precluded by a recent study that found extremely low concentrations of cosmogenic ${ }^{10} \mathrm{Be}$ and ${ }^{26} \mathrm{Al}$ isotopes in the ANDRILL-1B marine sediment core (Shakun et al. 2018).

If all the variability in the PlioSeaNZ record was above present-day sea level, then GMSL during the warmest mid-Pliocene interglacial was at least $+4.1 \mathrm{~m}$ and no more than $+20.7 \mathrm{~m}$, with a median of $+10.7 \mathrm{~m}$ and likely (66\%) range between $6.2 \mathrm{~m}$ (16th percentile) and $16.7 \mathrm{~m}$ (84th percentile; Fig. 2b). This maximum range is consistent with sediment composition from polar continental sediment cores, far-field sea-level reconstructions (Fig. 2b and refs. therein), and icesheet model constraints (e.g. DeConto and Pollard 2016). On this basis, we suggest that estimates using a calibration of the deep-sea $\delta^{18} \mathrm{O}$ record by $\mathrm{Mg} / \mathrm{C}$ a paleothermometry and a sill depth-salinity relationship tend to overestimate the amplitude of global sealevel change during the MPWP.

This range also implies an equilibrium polar ice-sheet sensitivity of 2-8 $\mathrm{m}$ of sea-level change for every degree of temperature change, with a mean value of $4 \mathrm{~m} /{ }^{\circ} \mathrm{C}$. This empirical estimate does not consider icesheet dynamics, such as a potential stability threshold in the Antarctic Ice Sheet, caused by the loss of ice shelves, which may be crossed at $1.5-2^{\circ} \mathrm{C}$ of global warming, after which ongoing mass loss may be rapid and non-linear (Golledge et al. 2015).

\section{AFFILIATIONS}

'Department of Surface Geosciences, GNS Science, Lower Hutt, New Zealand

${ }^{2}$ Antarctic Research Centre, Victoria University of Wellington, New Zealand

\section{CONTACT}

Georgia Grant: G.Grant@gns.cri.nz

\section{REFERENCES}

DeConto RM, Pollard D (2016) Nature 531: 591-597

Dumitru OA et al. (2019) Nature 574: 233-236

Dutton A et al. (2015) Science 349: aaa4019

Dwyer GS, Chandler MA (2009) Philos Trans Royal Soc A 367: 157-168

Golledge NR et al. (2015) Nature 526: 421-425

Grant GR et al. (2019) Nature 574: 237-24

Lisiecki LE, Raymo ME (2005) Paleoceanography 20: PA1003

Masson-Delmotte V et al. (2013) In: Stocker TF et al. (Eds) Climate Change 2013: The Physical Science Basis. Cambridge University Press, 383-464

Miller KG et al. (2012) Geology 40: 407-410

Miller KG et al. (2020) Science 6: eaaz1346 Naish TR et al. (2009) Nature 458: 322-328

Naish TR, Wilson GS (2009) Philos Trans Royal Soc A 367 : 169-87

Raymo ME et al. (2011) Nature Geosci 4: 328-332

Rohling EJ et al. (2014) Nature 508: 477-482

Rovere A et al. (2015) Earth Sci Rev 145: 117-131

Shakun JD et al. (2018) Nature 558: 284-287

Sosdian S, Rosenthal Y (2009) Science 325: 306-310

Thiede J et al. (2011) Polarforschung 80: 141-159 